\title{
Fabrication of Aluminum Coating onto CFRP Substrate by Cold Spray
}

\author{
Jon Affi*, Hiroki Okazaki*, Motohiro Yamada and Masahiro Fukumoto \\ Department of Mechanical Engineering, Toyohashi University of Technology, Toyohashi 441-8580, Japan
}

Carbon fiber-reinforced plastic (CFRP) has a great potential application in aircraft fuselage due to its light weight, high specific stiffness and high specific strength. It is crucial to coat the CFRP surface with an electrically conductive material to avoid the damage from lightning strike. Cold spray process has been developed for metallic coating technique. In this study, aluminum coating was fabricated onto the CFRP substrate using interlayer was investigated. It was difficult to fabricate cold-sprayed aluminum coating directly on the CFRP substrate. Though smaller size aluminum particles could be deposited on the CFRP substrate, but the coating was peeled off when the thickness was around $30 \mu \mathrm{m}$. On the other hand, it was possible to deposit aluminum coating on the CFRP substrate by plasma spray process. Our proposed structure is using a thin plasma-sprayed aluminum interlayer on the CFRP substrate before doing the cold spray. The interlayer with larger contact area could retain on the substrate and able to facilitate the deformation of the next incoming cold-sprayed particles to build a thick coating. The volume resistivity of cold spray coating is lower than the plasma sprayed aluminum coating because of high process gas temperature in the latter case enhances the oxidation of sprayed particle. Therefore, lower process gas temperature should be used to fabricate lower volume resistivity coating on cold spray. [doi:10.2320/matertrans.T-M2011807]

(Received March 2, 2011; Accepted June 27, 2011; Published August 10, 2011)

Keywords: carbon fiber-reinforced plastic (CFRP), aluminum coating, cold spray, interlayer, volume resistivity

\section{Introduction}

Carbon fiber-reinforced plastic (CFRP) has become a high demand material in structures and components especially for aircraft bodies due to its low density, high specific strength and high specific stiffness. ${ }^{1-3)}$ It has been developed as mechanical components to replace some metallic materials for aircraft structure. When applying CFRP on an aircraft body, a surface conductive path is required to avoid the damage from lightning strike and thunderstorm electric field attack. ${ }^{4)}$ The electrical conductive path can be provided by performing metallic coating on the CFRP surface.

Electroplating process can be used to build coating on the CFRP. However, a direct electroplating process on CFRP is impossible due to non-conductive behavior of the outer surface. ${ }^{1)}$ Hence, another conductive undercoat layer must be applied before doing the electroplating. This process is effective for thin coating. However, to build a thick coating requires several steps and several hours to complete. Also the process results more waste and hazard materials to the environmental and human bodies. Some countries have made strict regulations to use the electroplating process.

Thermal spray process is well known for large area coating. However, the volume resistivity of the thermalsprayed metallic coating is much higher than the bulk material, which is undesirable especially for lightning protection application. ${ }^{5)}$ It is caused by the oxidation of sprayed particles in the atmospheric ambient. On the other hand, cold spray process has been developed as a high-quality metallic coating technique. In this technique, metallic feedstock particles are accelerated by a supersonic gas stream at lower temperature and deposited on a substrate as solid phase. This process can prevent the oxidization of sprayed metallic materials during deposition. Hence, the cold spraying is considered to be an ideal process for fabrication of electrical conductive metallic coating onto CFRP surface. However,

*Graduate Student, Toyohashi University of Technology fabrication of metallic coating on the CFRP substrate by cold spraying is difficult. ${ }^{6)}$ In CFRP, the plastic is reinforced with the carbon fibers. Both plastic and carbon fibers are easily eroded by high energy collision of cold-sprayed particles. This paper will discuss a direct cold spray aluminum coating on the CFRP substrate and the possibilities of using a plasma sprayed interlayer to develop high dense aluminum coating.

\section{Experimental Procedure}

The cold spray system used in this study was self-designed and custom manufactured using de-Laval barrel nozzle. Nitrogen was used as process gas. Spraying parameters are shown in Table 1. Commercially pure aluminum powders of two different sizes were used (Toyo Aluminum K. K. Co. Ltd) as the feedstock materials. As can be seen from the Fig. 1, the sizes of the powders are $3 \mu \mathrm{m}$ and $15 \mu \mathrm{m}$. CFRP plate (provided by Mitsubishi Rayon, Co. Ltd) was used as a substrate. It has been made up of airplane grade epoxy resin having heat resisting temperature of $180^{\circ} \mathrm{C}$ and PAN based carbon fiber as reinforcement (TR50S-6L). Details of CFRP composite are shown in Table 2. An atmospheric plasma spray system (APS: 9MB, Sulzer Metco) was used for making interlayer. The process conditions are given in the Table 1. Long spray distance and sufficient substrate cooling procedure were used to avoid CFRP surface damage by high temperature. Observation of coating surface and cross section was conducted using scanning electron microscope (SEM: JSM-6390TY, JEOL Co. Ltd.). The volume resistivity of sprayed coatings was measured by four probe (terminals) methods. The two outer probes were used for sourcing current and the two inner probes were used for measuring the resulting voltage drop across the surface of the sample. To calibrate unit volume resistivity per-unit area cross-section, the measurement was performed at several points with different distance of inner probe as shown in Fig. 2. Each sample was measured three times and the average value was taken as a representative result. 
Table 1 Typical plasma and cold spray condition.

\begin{tabular}{|c|c|c|}
\hline \multicolumn{3}{|c|}{ Process Parameter Plasma Spray Interlayer } \\
\hline \multirow[t]{2}{*}{ Primary Gas (Ar) } & Pressure (MPa) & 0.52 \\
\hline & Flow Rate $(1 /$ minute $)$ & 0.050 \\
\hline \multirow[t]{2}{*}{ Primary Gas (Ar) } & Pressure (MPa) & 0.35 \\
\hline & Flow Rate $(1 /$ minute $)$ & 0.028 \\
\hline \multicolumn{2}{|l|}{ Arc Current (A) } & 500 \\
\hline \multicolumn{2}{|l|}{ Arc Voltage (V) } & 56 \\
\hline \multicolumn{2}{|c|}{ Spray Distance (mm) } & 150 \\
\hline \multicolumn{2}{|c|}{ Traverse Speed (mm/s) } & 202 \\
\hline \multicolumn{2}{|c|}{ Powder and Size $(\mu \mathrm{m})$} & $\mathrm{Al}$ and 15 \\
\hline \multicolumn{2}{|l|}{ Traverse Times } & 3 \\
\hline \multicolumn{2}{|c|}{ Carrier Gas and Flow Rate (1/minute) } & Ar and 0.024 \\
\hline \multicolumn{3}{|c|}{ Process Parameter for Cold Spray Coating } \\
\hline \multicolumn{2}{|c|}{ Gas temperature $\left({ }^{\circ} \mathrm{C}\right)$} & $300-600$ \\
\hline \multicolumn{2}{|c|}{ Gas Pressure (MPa) } & $0.5-2$ \\
\hline \multicolumn{2}{|c|}{ Spray Distance (mm) } & 20 \\
\hline \multicolumn{2}{|c|}{ Powder feed rate (g/minute) } & 6 \\
\hline \multicolumn{2}{|c|}{ Traverse speed $(\mathrm{mm} / \mathrm{s})$} & 20 \\
\hline \multicolumn{2}{|l|}{ Pass number } & $3-6$ \\
\hline
\end{tabular}

Table 2 The properties of CFRP composite.

\begin{tabular}{ll}
\hline Fiber Trade Name & TR50S-6L Diameter $7 \mu \mathrm{m}$ \\
\hline Fiber Tow Size & 24000 \\
\hline Fiber Density & $1.82 \mathrm{~g} / \mathrm{cm}^{3}$ \\
\hline Linear Mass Density & $400 \mathrm{mg} / \mathrm{m}$ \\
\hline Strength & $4900 \mathrm{MPa}$ \\
\hline Modulus & $240 \mathrm{GPa}$ \\
\hline Matric & Airplane Grade Epoxy \\
\hline Curing Temperature & $180^{\circ} \mathrm{C}$ \\
\hline Composite Structure & Satin Pattern \\
\hline Tow Density $/ 25 \mathrm{~mm}$ & Vertical 8.75 and Horizontal 8.75 \\
\hline Layer & 8 \\
\hline Mass per Unit Area & $280 \mathrm{~g} / \mathrm{mm}^{2}$ \\
\hline Lay-Up Sequence of Layer & {$[+45 / 90 /-45 / 90] /[90 /-45 / 90 /+45]$} \\
\hline
\end{tabular}

\section{Results and Discussion}

\subsection{Cold spraying of aluminum directly on the CFRP substrate}

Cold sprayed aluminum powders could not be deposited directly on the CFRP surface, when using the gas temperature of $300^{\circ} \mathrm{C}$ to $600^{\circ} \mathrm{C}$ and the particle size of $15 \mu \mathrm{m}$. In these conditions, severe erosion was observed on the CFRP substrate. Several researchers also confirmed that the adherence of the sprayed aluminum powder onto the plastic substrate is difficult. ${ }^{67)}$ Especially, according to Lupoi et al. ${ }^{7)}$ the most important factor for cold sprayed metallic adhering ability on the plastic is the particle impact energy (particle mass and velocity). This report shows that the impact energy required for a single sprayed particle to attach with the plastic substrate should be less than $0.002 \mathrm{~mJ}$. The
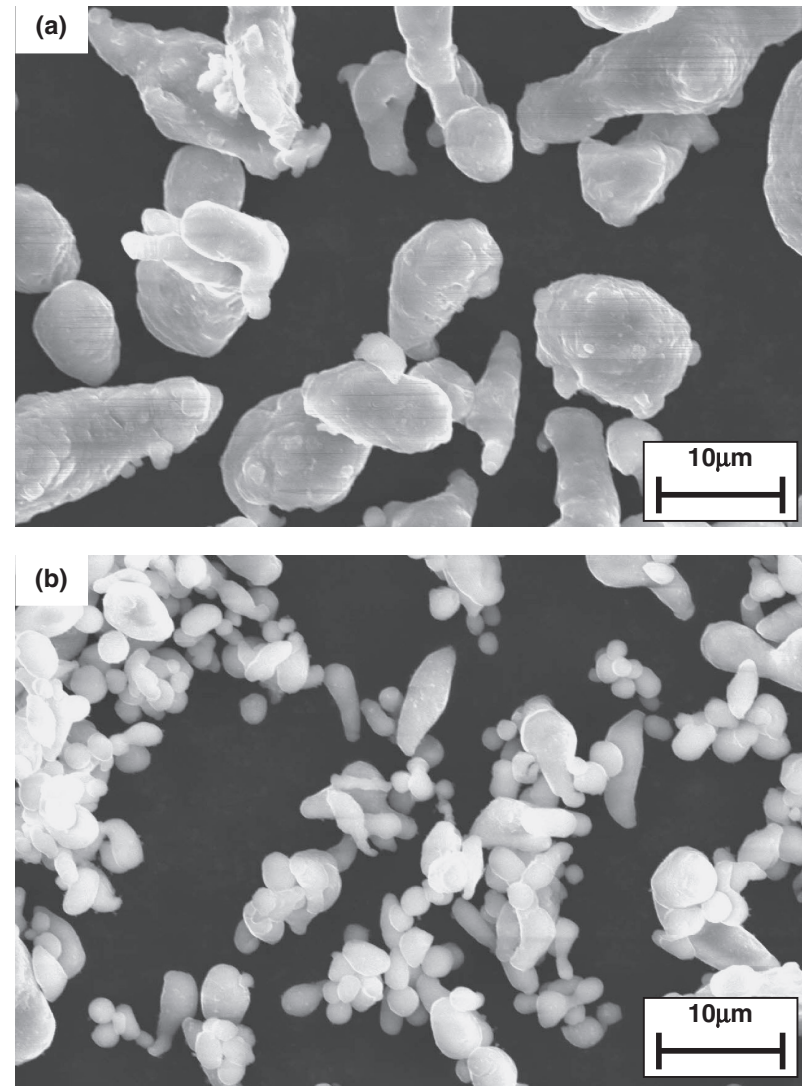

Fig. 1 SEM images of feedstock aluminum powders with particle size of (a). $15 \mu \mathrm{m}$ (b). $3 \mu \mathrm{m}$.

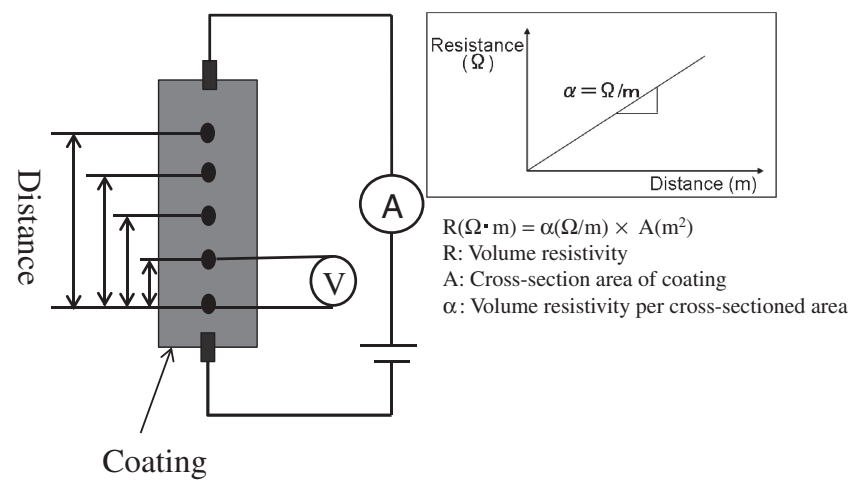

Fig. 2 Schematic measurement of volume resistivity on coating.

lower impact energy can be achieved by lower velocity and relatively soft metallic particles. However, deformation of particle is still required during collision even with lower impacting energy. Therefore, only a softer metallic material such as tin or lead can be deposited onto plastic substrate due to lower impacting energy. In the case of cold spraying aluminum on the CFRP substrate, the plastic deformation of aluminum particles that required for adhering on plastic substrate was not occurred. The CFRP substrate was eroded by aluminum particles with size of $15 \mu \mathrm{m}$ due to very high impact energy during collision. Hence, in order to fabricate aluminum coating on the CFRP substrate, the impacting energy of sprayed particles must be decreased.

The impacting energy is strongly affected by the particles properties such as density, shape, size. Therefore, cold 


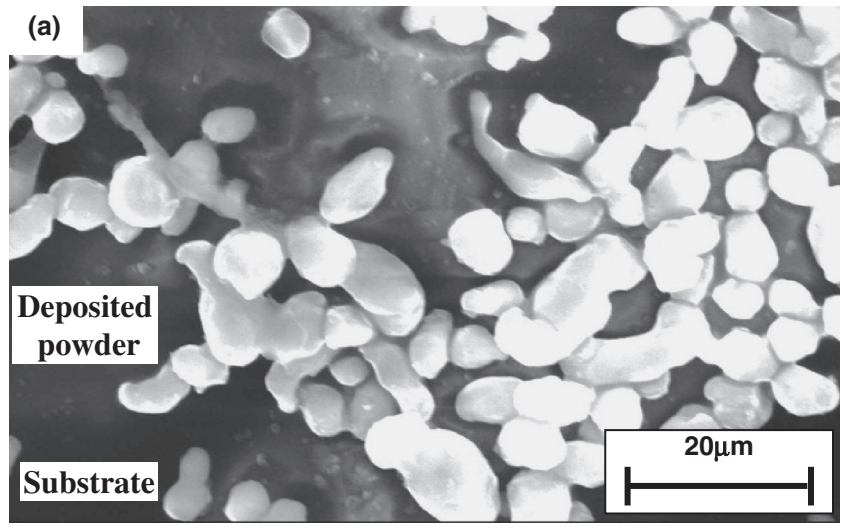

(b)

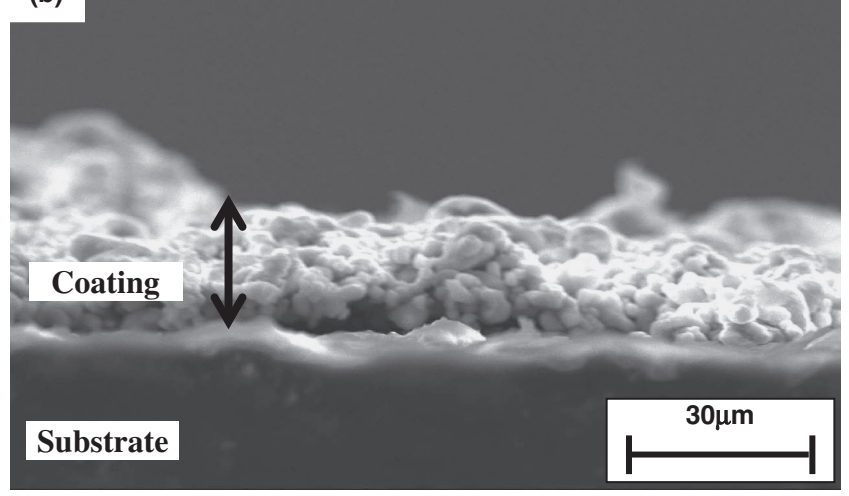

(c)

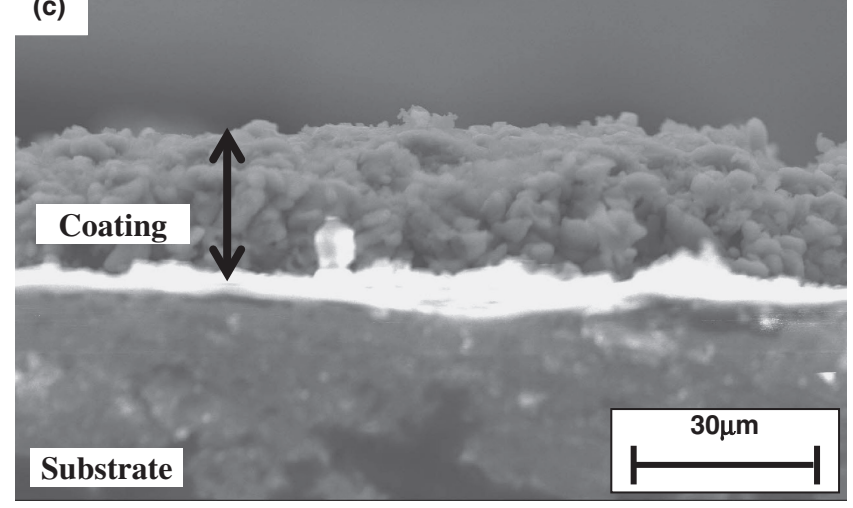

Fig. 3 SEM images of cold-sprayed aluminum particles on CFRP substrate with gas temperature of $600^{\circ} \mathrm{C}$ and gas pressure of (a) $0.5 \mathrm{MPa}$ (top view), (b) $1 \mathrm{MPa}$ (cross section), and (c) $2 \mathrm{MPa}$ (cross section).

spraying of smaller aluminum particles with the size of $3 \mu \mathrm{m}$ was attempted. The result shows that cold spraying with the process gas temperature between $300^{\circ} \mathrm{C}-500^{\circ} \mathrm{C}$, there were no deposition on the substrate. However, some particles were deposited on the CFRP substrate with the gas temperature of $600^{\circ} \mathrm{C}$ as shown in Fig. 3. Higher process gas temperature may increase the ductility of sprayed powder during flight in the gas stream. In this temperature, the deposition of softened particles could be also enhanced by increasing the particle velocity by increasing gas pressure. Figure 3(a) shows that several powders were able to deposit on CFRP surface using process gas pressure of $0.5 \mathrm{MPa}$ (top surface). The powders were attached to the matrix surface, where we observed the excessive matrix deformation and without any recognizable powder deformation. Figures 3(b)-(c) show cross-section of coating sprayed with the gas pressure of 1 and $2 \mathrm{MPa}$

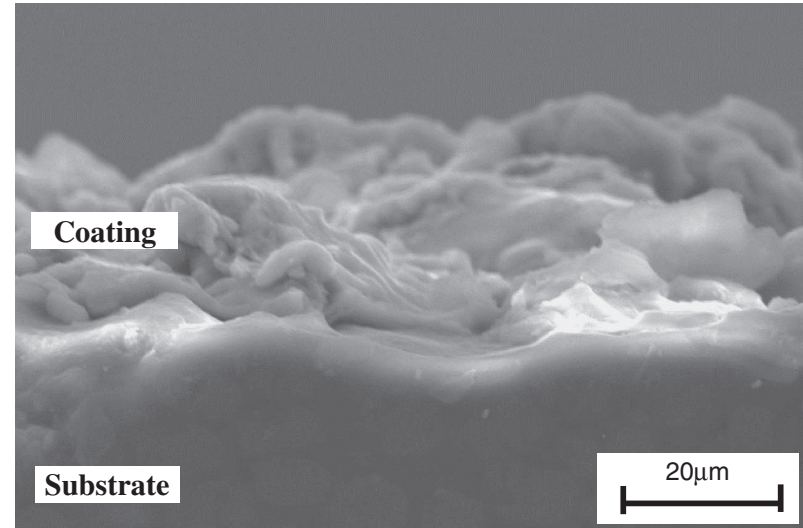

Fig. 4 SEM image of atmospheric plasma sprayed aluminum with feedstock particle size of $15 \mu \mathrm{m}$ onto the CFRP substrate.

respectively. Unfortunately, the coating peeled off from the substrate when the coating thickness closes to $30 \mu \mathrm{m}$. The peeling off during spraying removes the plastic matrix from the CFRP and exposes the carbon fibers. The exposed carbon fibers are not suitable for particle deposition due to lack of rigidity. Therefore, cold spraying of aluminum particles directly onto CFRP substrate is considered as difficult.

\subsection{Cold spraying of aluminum onto plasma-sprayed interlayer}

There are some reports about fabrication of metallic coatings on the CFRP substrate by plasma spraying. ${ }^{8,9)}$ In this work, plasma sprayed aluminum coating was used as an interlayer before the cold spraying process. A plasmasprayed aluminum coating on the CFRP substrate is shown in Fig. 4. The thickness of the coating was less than $15 \mu \mathrm{m}$. A thin interlayer is sufficient to facilitate the deformation of cold-sprayed particles. Moreover, the thin interlayer should not affect the electrical properties of the coating.

Figure 5 shows the cross-sectional microstructure of coldsprayed aluminum coatings on the interlayer under the gas temperature of 300 to $400^{\circ} \mathrm{C}$ and gas pressure of $0.5 \mathrm{MPa}$. This result clearly reveals that using an interlayer improves the deposition of cold-sprayed aluminum particles. Thick and dense coatings were successfully fabricated on CFRP substrate under all gas temperature.

The interlayer metallic coating was a key point for the deposition of cold-sprayed metallic particles. The impact energy of sprayed particles may be utilized for particle deformation in the interlayer as well as the impacting particle. The above stated phenomenon is much similar to the bonding mechanism for the cold spray coating on the metallic substrate. Moreover, there is no erosion occurring between sprayed particle and plasma sprayed interlayer. It can be stated that erosion properties of CFRP substrate was improved significantly by using plasma sprayed interlayer.

\subsection{Bonding mechanism}

Critical velocity of sprayed particles is an important criterion on cold spray processing to fabricate metallic coatings on the metallic substrate. The higher particle velocity is required to provide sufficient impact energy during collision for breaking out of the oxide layers on both 


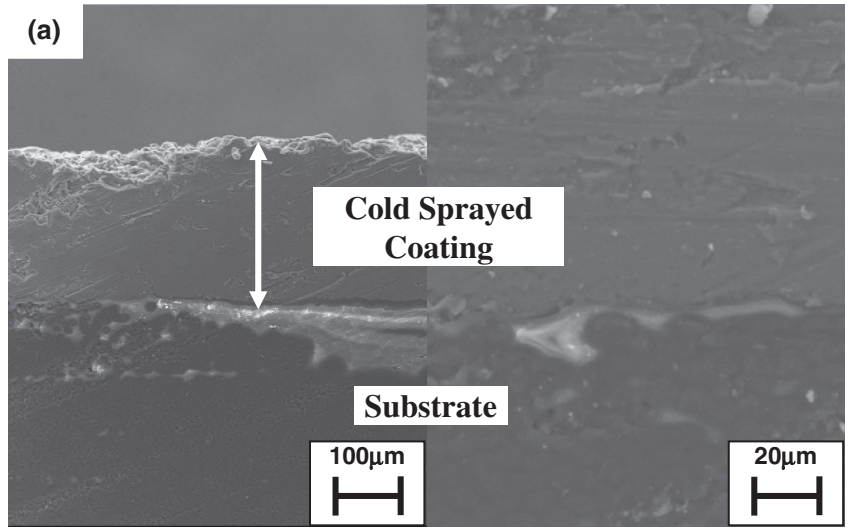

(b)

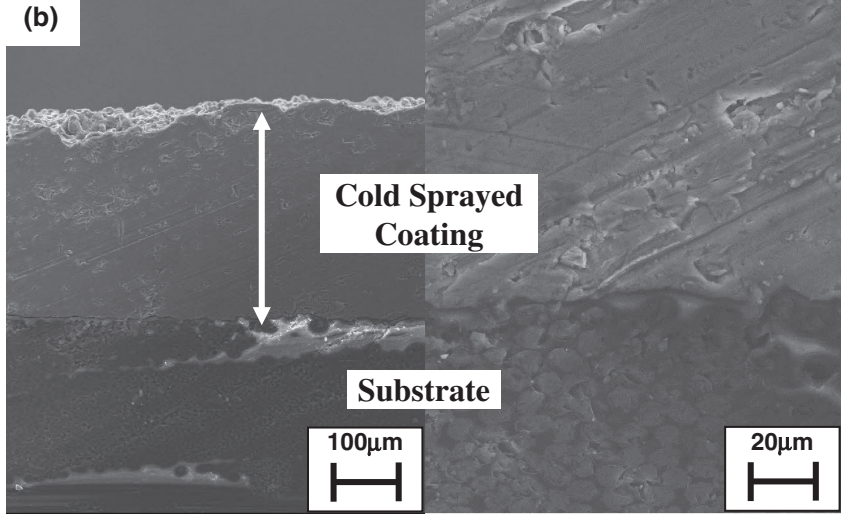

(c)

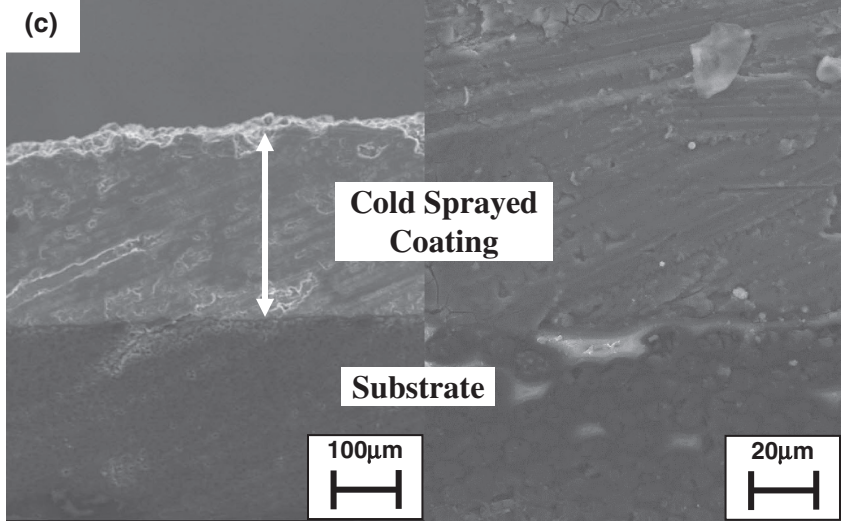

Fig. 5 The cross sectional SEM images of aluminum cold sprayed coated onto CFRP substrate with atmospheric plasma sprayed interlayer and their cold spray parameter are as follows: a. $300^{\circ} \mathrm{C}, 6$ Passes; b. $350^{\circ} \mathrm{C}, 5$ Passes; c. $400^{\circ} \mathrm{C}, 3$ Passes.

particle and substrate surface then producing real metallic bond. ${ }^{10,11)}$ In other words, plastic deformation of both sprayed particle and substrate surface is required to obtain a strong bonding on cold spray process. On the contrary, deposition behavior of metallic particle on plastic substrate is limited for particle with lower critical velocity. ${ }^{7)}$ Furthermore, we cannot expect the metallic bond between metallic particle and plastic substrate. In this study, the smaller diameter aluminum particles were deposited directly on CFRP substrate as shown in Fig. 3. However the deposited particles were maintained original spherical shape without significant flattening deformation. Without the sufficient deformation, the adhesion contact area between the particle and the substrate is appeared to be small. In the same time, it is hard to understand the formation of mechanical anchoring

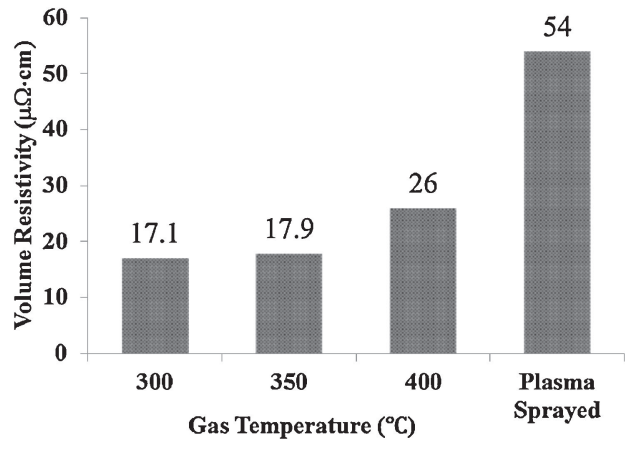

Fig. 6 Volume resistivity of aluminum cold sprayed onto CFRP.

between the coating and the substrate with the small deformation of particles and excessive substrate deformation. In the between aluminum particle and CFRP substrate combination, therefore, the bonding mechanism is considered to be a physical bond i.e., van der Waals force. The adhesion area is quite important to perform higher adhesion strength on this bonding. The plasma-sprayed aluminum particles are also bonded with physical bond in this material combination. However, the molten particles can easily form larger contact area as compared with the cold sprayed particles. Normally, cold sprayed aluminum particles on the harder substrate materials can be deformed and yield large contact area. However, the soft plastic on the CFRP substrate absorbs the impact energy of sprayed particles and, then yields smaller contact area as shown in Fig. 3. The coating can be easily peeled off due to this small contact area and the increasing thickness due to thermal shrinkage. The plasma spayed aluminum interlayer with larger contact area could be retained on the substrate and able to facilitate the deformation of the incoming cold-sprayed particles to build a thick coating, consequently.

\subsection{Electrical property of coatings}

Aluminum is a well-known material with low volume resistivity that useful for avoiding the damage from lightning attack in airplane. When using composite carbon fiber embedded in plastic matric, the resistance will be 2000 times larger than resistance of aluminum, which has a resistance of $2.8 \mu \Omega-\mathrm{cm} .{ }^{12)}$ The lightning attack with high enough current density may be dissipated through heat and make degradation on plastic matrix. Hence, low volume resistivity of aluminum coating is required on CFRP surface for lightning protection. Figure 6 shows the volume resistivity of coating fabricated by both plasma and cold spraying. Plasma sprayed coating has high volume resistivity than cold-sprayed aluminum. It is significantly affected by the porosity and oxide content in the coating. ${ }^{13)}$ By using cold spray with gas pressure $0.5 \mathrm{MPa}$, the volume resistivity of the coatings was increased slightly with the increasing process gas temperature from 300 to $350^{\circ} \mathrm{C}$. The volume resistivity should be improved by using higher process gas temperature because of more densified microstructure through higher particle velocity. Unfortunately, the volume resistivity was increased significantly for cold sprayed coating using proses gas temperature of $400^{\circ} \mathrm{C}$. The cross section observation was performed to clarify this phenomenon. Figure 5 with higher magnification shows no 
significant difference in the porosity between coatings with cold spraying at various process gas temperatures. However, the higher volume resistivity may be caused by more oxidation of sprayed particles at higher gas temperature.

\section{Conclusions}

In this study, cold spray process was conducted to fabricate aluminum coating onto CFRP substrate. The usage possibility of plasma-sprayed interlayer prior to cold spray was also investigated. The results obtained in this study are summarized as follows:

(1) Smaller particle size $(3 \mu \mathrm{m})$ of aluminum particles were deposited directly on the CFRP substrate by cold spray process within the coating thickness of $30 \mu \mathrm{m}$.

(2) It is possible to fabricate thick aluminum coating onto CFRP substrate by cold spray process with the addition of thin plasma-sprayed aluminum interlayer. The interlayer with larger contact area could be retained on the substrate and able to facilitate the deformation of the incoming cold-sprayed particles to build a thick coating.

(3) The volume resistivity of the coating fabricated by cold spray is lower than that of plasma sprayed aluminum coating, though higher gas temperature enhances the oxidation of sprayed particle. Lower gas temperature should be used to fabricate lower volume resistivity coating on cold spray.

\section{Acknowledgment}

The airplane grade of CFRP substrates were provided by Mitsubishi Rayon Co. Ltd. The authors wish to acknowledge Mitsubishi Rayon Co. Ltd for this study supporting.

\section{REFERENCES}

1) M. Menningen and H. Weiss: Surf. Coat. Technol. 76-77 (1995) 835840.

2) C. Soutis: Mater. Sci. Eng. A 412 (2005) 171-176.

3) C. K. Lee: Mater. Chem. Phys. 114 (2009) 125-133.

4) S. A. Baldacim, N. Cristofani, J. L. F. Junior and J. R. Lautenschlager: $17^{\circ}$ CBECImat-Congresso Brasileiro de Engenharia e Ciência dos Materiais, (Foz do iguaçu, PR, Brazil, 2006) pp. 3247-3258.

5) T. Stoltenhoff, C. Borchers, F. Gärtner and H. Kreye: Surf. Coat. Technol. 200 (2006) 4947-4960.

6) D. Zhang, P. H. Shipway and D. G. McCartney: J. Therm. Spray Technol. 14 (2005) 109-116.

7) R. Lupoi and W. O'Neill: Surf. Coat. Technol 205 (2010) 2167-2173.

8) R. Beydon, G. Bernhart and Y. Segui: Coat. Technol. 126 (2000) 3947.

9) F. Decla, S. Leroux, G. Bernhart, C. Levaillant and N. Frety: Surface Modification Technologies XI (UK), (1998) pp. 293-299.

10) H. Assadi, F. Gärtner, T. Stoltenhoff and H. Kreye: Acta Mater. 51 (2003) 4379-4394.

11) H. Nakano, M. Yamada, M. Fukumoto and E. Yamaguchi: J. Therm. Spray Technol. 20 (2011) 407-411.

12) J. A. Plumer and J. D. Robb: IEEE Trans. Electromagn. Compat. 24 (1982) $158-172$

13) M. P. Planche, H. Liao and C. Coddet: Surf. Coat. Technol. 202 (2007) 69-76. 